\title{
Late complications of hemispherectomy: report of a case relieved by surgery
}

\author{
NINAN T. MATHEW, JACOB ABRAHAM, AND JACOB CHANDY
}

\author{
From the Department of Neurological Sciences, Christian Medical College Hospital, Vellore, S. India
}

SUMMARY A case of Sturge-Weber disease treated with left hemispherectomy presented, 11 years later, with complications related to delayed intracranial haemorrhage. A loculation syndrome of the $\frac{\bar{\rho}}{\partial}$ right lateral ventricle was detected and it was corrected by a ventriculoatrial shunt operation. The $\propto$ side of the hemispherectomy was evacuated of all the chronic products of haemorrhage, including $\infty$ the subdural membrane. The patient was relieved of her symptoms. It is considered that compli- $\overrightarrow{0}$ cations related to delayed haemorrhage after hemispherectomy are remediable.

Immediate and delayed complications occur after hemispherectomy. Early complications include obstructive hydrocephalus and herniations of the remaining hemisphere (Cabieses, Jerí, and Landa, 1957; Laine, Pruvot, and Osson, 1964). A syndrome of delayed intracranial haemorrhage was reported by Oppenheimer and Griffith (1966). The essential features of the syndrome are (1) an infantile hemiplegia treated by hemispherectomy; (2) a troublefree period lasting for some years; (3) a period of deterioration, extending over several years and ending in death; during this period, evidence of bleeding into cerebrospinal fluid (CSF) pathways and later of obstructive hydrocephalus is found; (4) post-mortem findings of superficial haemosiderosis of the central nervous system; chronic granular ependymitis, leading to obstruction of cerebrospinal fluid pathways; and evidence of multiple bleeding points in the membrane which had replaced the missing hemisphere and in the extension of this membrane on to the lining of the ventricular system.

Falconer and Wilson (1969) reviewed the literature and reported four cases of delayed complications after hemispherectomy, of which three were relieved by surgery. They described a hitherto undescribed complication of hemispherectomy-namely, 'loculation' of the residual temporal horn.

This paper reports a case with complications related to delayed haemorrhage after hemispherectomy which was successfully relieved by ventriculoatrial shunt and reoperation.

\section{CASE REPORT}

A.L., a 17-year-old girl, was admitted to the Neurology service of Christian Medical College Hospital, Vellore, on
10 July 1969, with persistent headache, vomiting, and increasing drowsiness of three weeks' duration. She was? born with a Sturge-Weber syndrome and had had a left hemispherectomy performed in another country 11 yeas before. She was free from seizures and major behaviour $w$ problems and was attending a school for backwa@ $N$ children till November 1968, when she developed seves constant headache, vomiting, and drowsiness. She was admitted elsewhere in early December 1968, where brownish yellow fluid with a protein content of $1,150 \mathrm{mg}$ $100 \mathrm{ml}$. was tapped from the left subdural space. Flut from the right lateral ventricle had a protein content $\vec{\sigma} \vec{\theta}$ $1,100 \mathrm{mg} / 100 \mathrm{ml}$. Lumbar puncture revealed xanth chromic CSF, with a protein content of $352 \mathrm{mg} / 100 \mathrm{ml}$. In six weeks, after repeated ventricular and lumbar punctures, her symptoms subsided. The lumbar CSF protein came down to $160 \mathrm{mg} / 100 \mathrm{ml}$. She remained well from the $\overline{0}$ middle of January 1969 to the end of June 1969. There was then a recurrence of symptoms, and a lumbar $\mathbb{Q}$ puncture on 28 June 1969 revealed clear fluid with a $\overrightarrow{\vec{\rho}}$ protein content of $73 \mathrm{mg} / 100 \mathrm{ml}$. Left subdural tap on 4 July 1969 revealed yellow blood-stained fluid with $3,000 \mathrm{mg} / 100 \mathrm{ml}$. protein. She was referred to our hospital for further management.

On admission she was bedridden, irritable, and extremely drowsy. She was disorientated in time and place and resented examination. Ocular fundi were pale. Left $\dot{0}$ 6 th nerve palsy was noticed. There was hemiatrophy of the right side with flaccid hemiparesis. A left facial naevus was found. On tapping the left subdural cavity brownish yellow fluid with 5 cells $/ \mathrm{c} . \mathrm{mm}$., protein $3.2 \mathrm{~g} / 100 \mathrm{ml}$, sugar $20 \mathrm{mg} / 100 \mathrm{ml}$., and chloride $560 \mathrm{mg} / 100 \mathrm{ml}$. was found. The fluid was sterile on culture. Right lateral $\frac{D}{2}$ ventricular CSF was clear, with $20 \mathrm{mg} / 100 \mathrm{ml}$. protein, $20 \mathrm{mg} / 100 \mathrm{ml}$. sugar, $590 \mathrm{mg} / 100 \mathrm{ml}$. chloride, and 1 cell/ $\overline{\mathrm{N}}$ c.mm. No organism was identified either by smear o examination or by culture. A lumbar puncture was not $N$ performed, as the lumbar CSF was reported to be normal N on 28 June. 
Radiographs of the skull revealed a left hemiatrophy with silver clips in various locations. A right carotid angiogram showed considerable shift of the anterior cerebral artery across the midline to the left side, a hydrocephalic pattern. and elevation of the middle cerebral artery (Fig. 1). A left carotid angiogram showed an ipsilateral shift of the anterior cerebral artery. Air injected into the right lateral ventricle filled it, but could not be induced to enter the left side. All parts of the right lateral ventricle were markedly dilated and showed a contralateral shift. Air introduced into the left subdural cavity showed multiple loculated spaces (Figs. 2,3, and 4). The right and the left sides were not communicating. The 3 rd ventricle, aqueduct, and 4th ventricle were not visualized. A diagnosis of delayed haemorrhage after hemispherectomy and resultant obstructive hydrocephalus involving the right lateral ventricle was made.

OPERATIVE PROCEDURES A ventriculoatrial shunt was performed on the right side on 18 July 1969 using a Pudenz-Heyer valve. The patient showed remarkable improvement after the shunt operation. Headache gradually disappeared and she became more alert.

A left parietal craniotomy was done on 23 July 1969. A very thick subdural membrane was found which in places was calcified. Multiple loculated areas containing xanthochromic fluid were seen to fill most of the cavity. Blood clots of varying ages were also found. The mem-

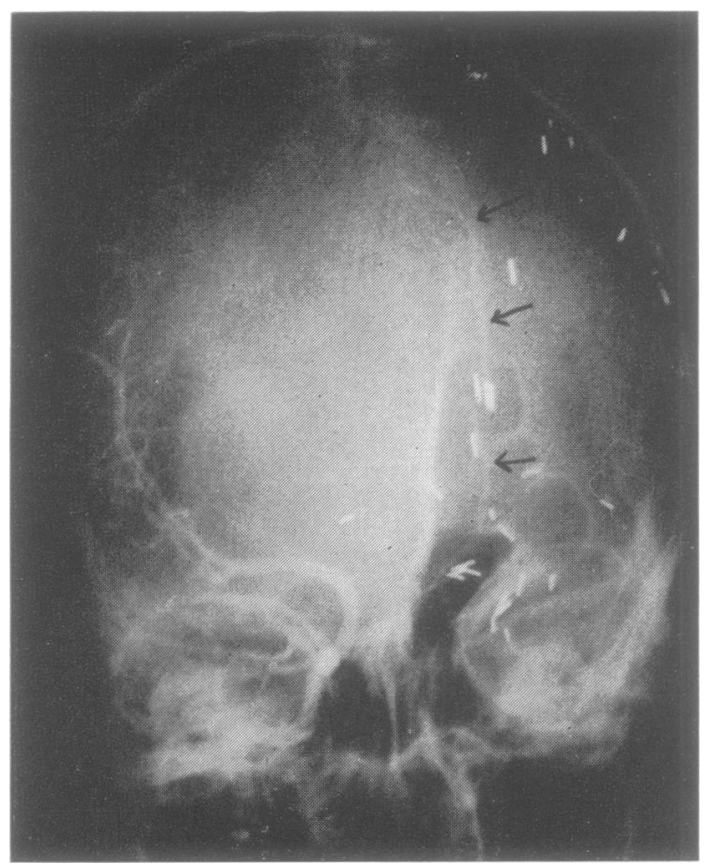

FIG. 1. Right carotid angiogram. Shift of the anterior cerebral artery to the left, elevation of middle cerebral artery, and hydrocephalic pattern on the right side. Silver clips are seen on the side of hemispherectomy.

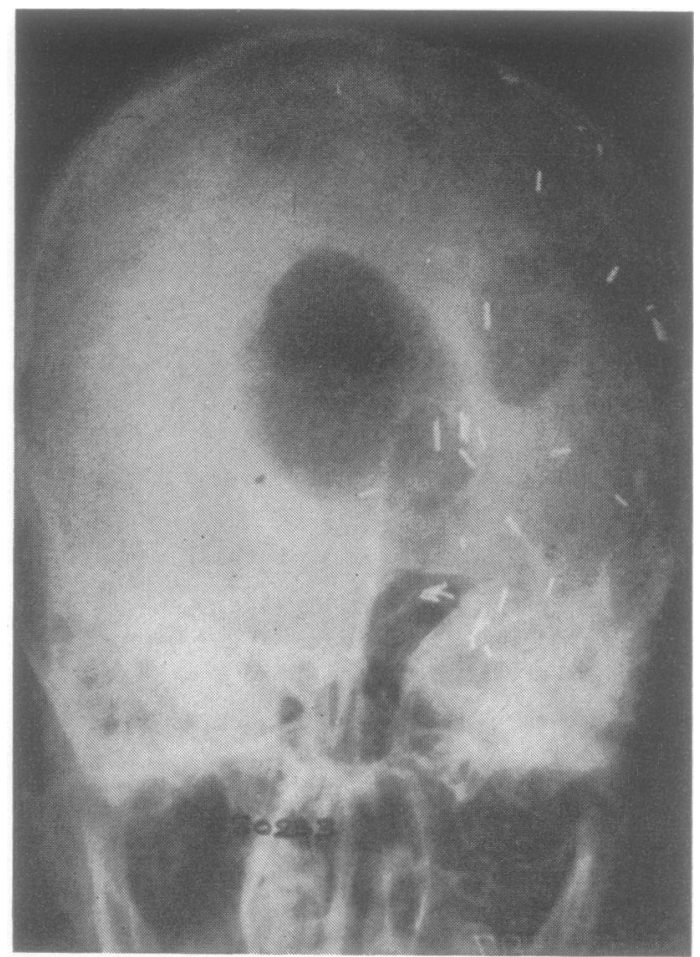

FIG. 2. Ventriculogram. Anteroposterior view: large dilated right lateral ventricle is shifted across the midline. Multiple loculated air-filled spaces are seen on the left side.

brane resembled that seen in chronic subdural haematoma (Fig. 5). Most of the membrane was excised except the medial part which was covering the basal ganglia. The whole cavity was evacuated and irrigated with Ringer solution. The dura was closed and the bone flap replaced.

Post-operatively, there was remarkable improvement. In $\mathbf{1 0}$ days after the operation she was talking and walking without support. There was no headache or vomiting. She showed interest in reading while in the hospital. She was discharged on 7 August 1969 and was reported to be doing well up to the preparation of this paper.

\section{DISCUSSION}

Oppenheimer and Griffith (1966) who first described the syndrome of delayed intracranial haemorrhage after hemispherectomy cited Falconer as saying that the condition can be treated surgically. Falconer and Wilson (1969) attributed the successful management of their cases primarily to removal of the products of haemorrhage rather than to attempts to create a normal CSF circulation by a shunt operation. They emphasized the point that these 


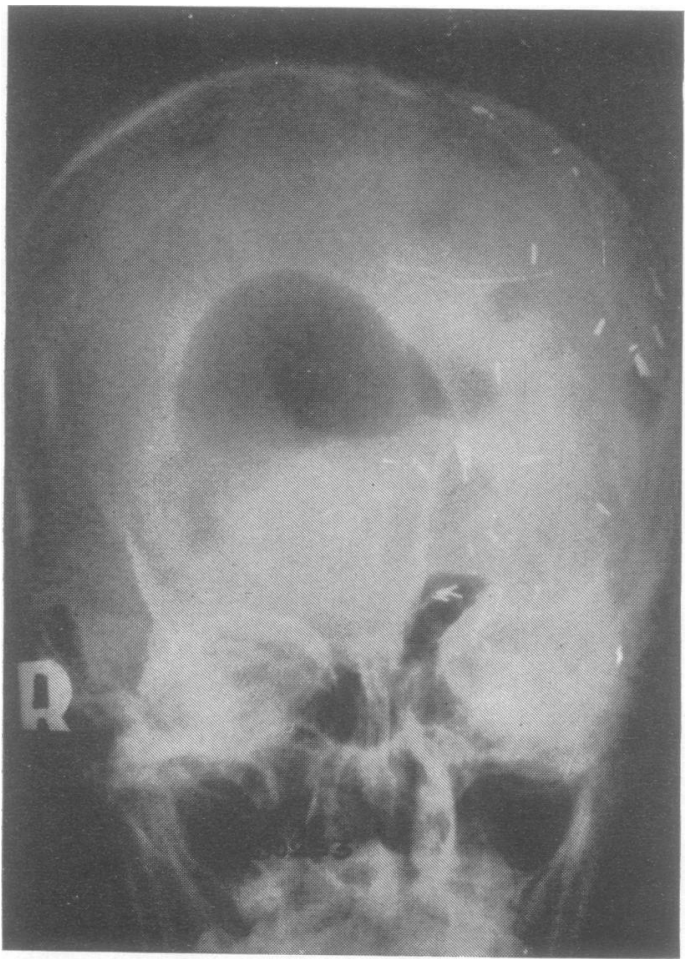

FIG. 3. Ventriculogram. Posteroanterior view: dilated right lateral ventricle, especially the occipital horn.

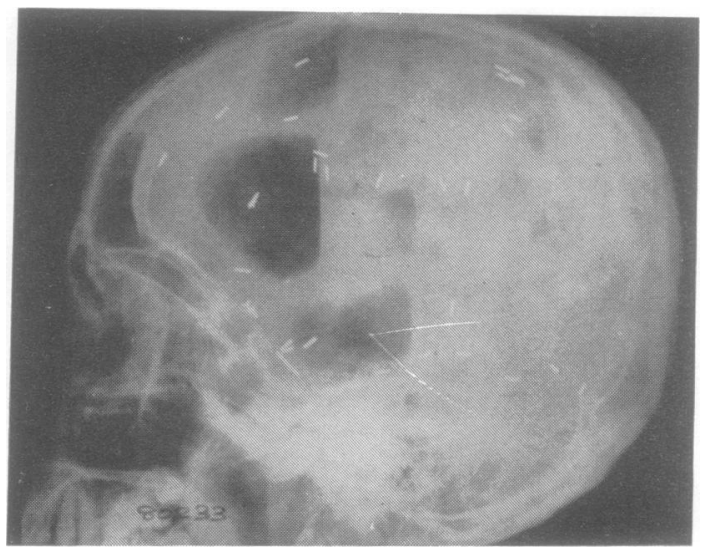

FIG. 4. Ventriculogram. Brow-up lateral view: dilated anterior and temporal horns of right lateral ventricle and loculated air spaces on the left side.

patients may be regarded as having a chronic encapsulated or membranous subdural haematoma. They have tried many surgical procedures including simple evacuation of the fluid compartment, opera tive removal of solid clot, and reduction of the aread of potential bleeding and exudative surface bxp 0 excision of as much membrane as is safely feasible $\stackrel{\varrho}{\square}$ In our case, the lumbar CSF and the CSF of the right ventricle were clear and were of a relatively

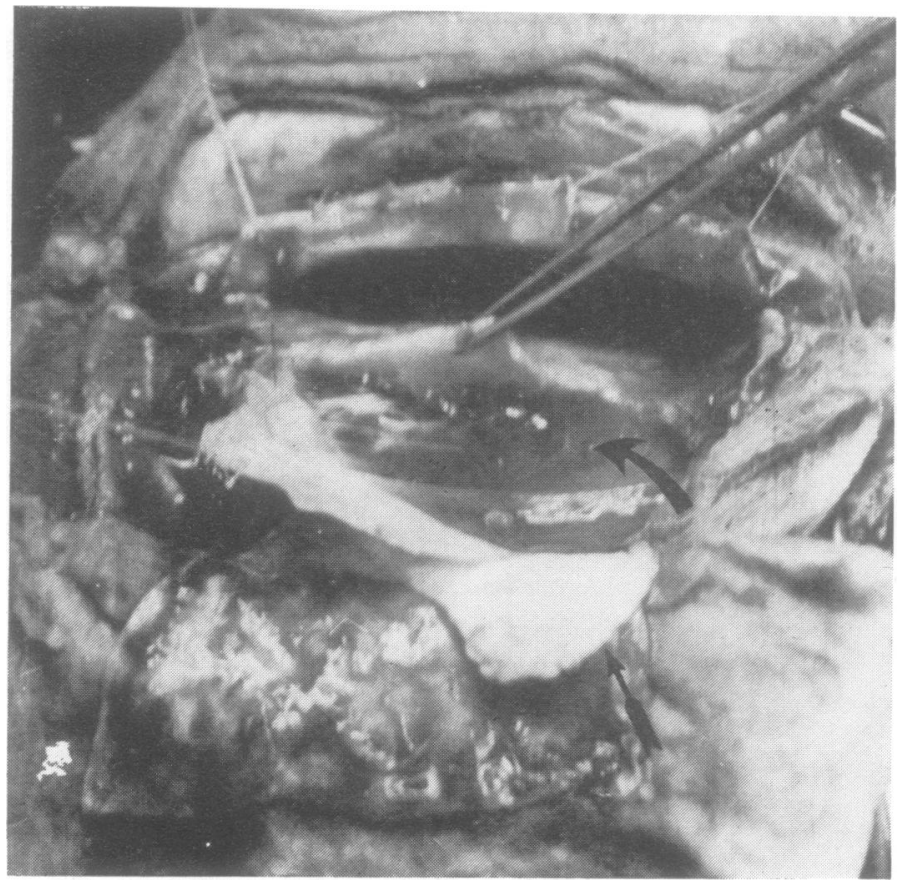

FIG. 5. Left parietal craniotomy. Thick subdural membrane is indicated by the straight arrow and the shiny loculated area of xanthochromic fluid collection by the curved arrow. 
normal composition, whereas the fluid in the left subdural cavity was brownish, blood stained, and had a high protein content. Ventriculography confirmed that the left cavity was not communicating with the right ventricle. The right ventricle was abnormally dilated and CSF was under increased tension, indicating that this patient had a 'loculation syndrome' of the right ventricle. 'Loculation syndrome' of the residual temporal horn requiring ventriculoatrial (VA) shunt was described by Falconer and Wilson (1969). In our case the loculation was not confined to the temporal horn, but involved the whole of the right lateral ventricle. Though the patient had considerable relief of symptoms after VA shunt, reoperation and evacuation of the left cranial cavity gave total relief of her symptoms.

We feel that in a case presenting with delayed complications after hemispherectomy, evidence of 'loculation syndrome' should be looked for and an appropriate shunt procedure performed. The cavity with haemorrhage and membrane should be dealt with separately, the best procedure being removal of as much membrane as possible and evacuation and lavage of the cavity. We agree with Falconer and Wilson (1969) who emphasized that the syndrome of delayed complications related to haemorrhage years after hemispherectomy is a remediable condition, provided a correct diagnosis is made early.

We thank Dr. H. M. Dastur, neurosurgeon, K. E. M. Hospital, Bombay, for giving us the details of the patient when she was under his care.

\section{REFERENCES}

Cabieses, F., Jerí, R., and Landa, R. (1957). Fatal brain-stem shift after hemispherectomy. J. Neurosurg., 14, 74-91.

Falconer, M. A., and Wilson, P. J. E. (1969). Complications related to delayed hemorrhage after hemispherectomy. J. Neurosurg., 30 , 413-426.

Laine, E., Pruvot, P., and Osson, D. (1964). Résultants éloignés de l'hémisphérectomie dans les cas d'hémiatrophie cérébrale infantile généractrice d'épilepsie. Neuro-chirurgie., 10, 507-522.

Oppenheimer, D. R., and Griffith, H. B. (1966). Persistent intracranial bleeding as a complication of hemispherectomy. J. Neurol. Neurosurg. Psychiat., 29, 229-240. 